\title{
宇宙機の最適なランテフに関するー覚意*1
}

\section{A Note on Optimal Spacecraft Rendezvous}

\author{
石 本 真 二*2 ・加藤 寛一 郎*3 \\ Shinji IsHIMOTo and Kanichiro KaTo
}

Key Words : Optimal Control Problems, Optimal Trajectory, Rendezvous, Numerical Methods

\begin{abstract}
This paper considers optimal rendezvous maneuvers to bring a spacecraft into close proximity of a target in circular orbit (typically a space station). The motion of the spacecraft relative to the target is described by linearized differential equations. Three optimal control problems are formulated using these equations. Optimal maneuvers minimizing energy, fuel, and time required for transfer are investigated and numerical solutions are shown employing SGRA (the sequential gradientrestoration algorithm).
\end{abstract}

\section{1.はじめに}

宇宙ステーションなどの軌道上の拠点を中心にして 行なわれる将来の宇宙開発を成功に緮くためには, 各 璉の宇宙機どうしのランデブ・ドッキングは久かすこ とはできない，本稿では，ランデブを行なう二つの宇 宙機がすでに十分に接近していると想定し，円軌道上 にある目標に向かって宇宙機を移動させるための最適 な制御を考察する。

このような問題に関しては，過去に複数のインパル スによる最適なランデブが多数研究されている(例え ぼ文献 1,2).しかし，推力を連続量として扱う解析 はほとんど行なわれていない。これは従来，最適制御 問題を数值的に解くことが困難であったためと考えら れる.

しかし，最近は二点境界值問題を解く優れたアルゴ リスムが開発されてきた。例えば，Mieleらの SGRA MQA 数值解でありながらほとんど簃密 解に近い精度で解を求めることができる。

本稿ではこのような数值解法を用い, 推力を連続量 として报うランデブ問題を考察する.本稿の目的は， いくつかの典型的なランデブ軌道を最適制御問題の解

\footnotetext{
"1 平成 2 年 6 月 2 日原稿受理

*2 東京大学大学院

*3 東京大学工学部航空学科
}

として示すことである。これによって評価関数とラン デブ軌道の関係が明確に把握できる。また，このよう な解は実用的なランデブ軌道を評価する際の基準とし ても有用である。

本稿の構成は次のようになっている，第 2 節では， ランデブの目標の近傍にある宇宙機が従う運動方程式 について述べる.目標に対する宇宙機の相対運動は， 線形化された運動方程式によって近似することができ る. 第 3 節では無次元の変数を䓕入し, 最適な轨道を 定める問題を最適制御問題として定式化する．第 4 節 では前節て定義された問題に対して最適解が满足すべ き必要条件を述へ，宇宙機が移動する際に必要なエネ ルギー，燃料，時間という三種類の典型的な評価関数 を最小にする最適な制御を示す．第 5 節では SGRA (the sequential gradient-restoration algorithm) と呼 ばれる数値解法によって得られた最適解の例を示す. 第 6 節では本稿のまとめを簡単に述べている。

\section{2. 運勁方程式}

ランデブを行なう宇宙機の運動を，第 1 図のような 目標宇宙機の上に原点を持つ座標系 $(x, y, z)$ で記述 することにする゙๋ 。この座標系では， $x$ 軸は目標の速 度べクトル方向に, $z$ 軸は地球の中心方向に, $y$ 軸は これらと右手系をなすようにとられている．ランデフ を行なう宇宙機が目標の十分近傍にある場合，その運 動は，引力項が目標のまわりに線形化された以下の線 形微分方程式で近似することができる゙．

$$
\begin{aligned}
& \ddot{x}=2 \omega_{0} \dot{z}+f_{x} \\
& \ddot{y}=-\omega_{0}^{2} y+f_{y} \\
& \ddot{z}=-2 \omega_{0} \dot{x}+3 \omega_{0}^{2} z+f_{z}
\end{aligned}
$$

ここで，・は時間に関する敃分を表し， $\omega_{0}$ は目標の 周回角速度， $f_{x} ， f_{y}, f_{z}$ は外力による加速度の各軸方 向成分てある。この運動方程式は, ClohessyWiltshireの方程式" あるいは Hill の方程式として知 られている. 推力による加速度は、最適制御問題の要 


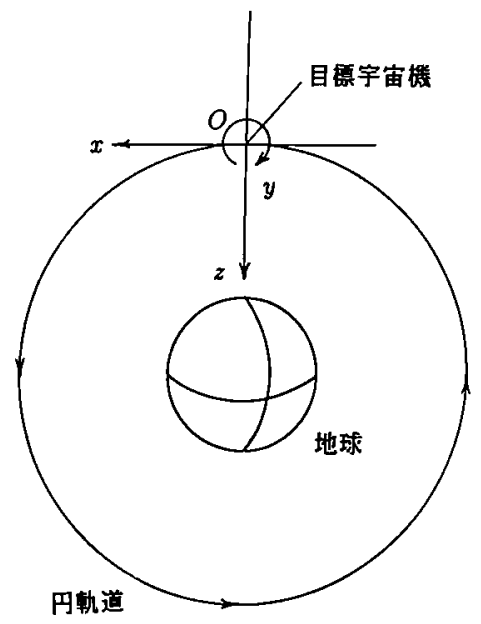

第 1 図 宇宙機の運動を記述するための座標系

請により区分的に連続な量で，その大きさが変化させ られるものと仮定する. また， $x z$ 面すなわ方軌道面 内の運動とそれに垂直な $y$ 軸方向の運動とは連成し ないので，宇宙機はつねに目標となる宇宙機の軌道面 内にあると仮定し,$y$ 軸方向の運動は考慮しない.

\section{3. 問題の定義}

簡潔な解析と安定した数值計算を行なうために，以 下のような無次元の変数を導入する.

$$
\begin{aligned}
& t=\omega_{0} \tau \\
& \boldsymbol{x}=\left[x_{1}, x_{2}, x_{3}, x_{4}\right]^{T}=\left[\frac{x}{l}, \frac{z}{l}, \frac{\dot{x}}{\omega_{0} l}, \frac{\dot{z}}{\omega_{0} l}\right]^{T} \\
& \boldsymbol{u}=\left[u_{1}, u_{2}\right]^{T}=\left[\frac{f_{x}}{\omega_{0}{ }^{2} l}, \frac{f_{2}}{\omega_{0}{ }^{2} l}\right]^{T}
\end{aligned}
$$

ここで, $\tau$ は次元を持つ現実の時間， $l$ は無次元化を 行なうための長さである。これら無次元の変数による 宇宙機の運動方程式は次のようになる。

$$
\frac{d x}{d t}=A x+B u
$$

ただし，

$$
\boldsymbol{A}=\left[\begin{array}{rrrr}
0 & 0 & 1 & 0 \\
0 & 0 & 0 & 1 \\
0 & 0 & 0 & 2 \\
0 & 3 & -2 & 0
\end{array}\right] \quad \boldsymbol{B}=\left[\begin{array}{ll}
0 & 0 \\
0 & 0 \\
1 & 0 \\
0 & 1
\end{array}\right]
$$

である。

上記の方程式によって運動が記述される宇宙機を時 刻 $t=0$ から時刻 $t=t_{f}$ まで制御するとき，次の評価 関数

$$
J=\int_{0}^{t s} f(u) d t
$$

を最小にするような制御入力
える. $f(\boldsymbol{u})$ の具体的な形は後に与える.ただし，初 期時刻における状態量 $x(0)$ と終端時刻における状態 量 $\boldsymbol{x}\left(t_{f}\right)$ は、いずれも，

$$
x(0)=x_{0} \quad x\left(t_{f}\right)=x_{f}
$$

のように与えられていて，制御入力 $\boldsymbol{u}$ には，

$$
|u| \leq u_{\max }
$$

という制限が加えられているものとする．ｕ而は推 力による加速度の上限を $\omega_{0}^{2} l$ によって無次元化した

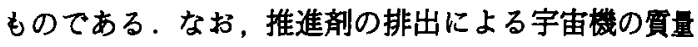
の変化は考慮せず，飛行中に $u_{\max }$ は変化しないもの と仮定する。

\section{4. 最小原理による最適制御の導出}

ポントリャーギン(Pontryagin)らの最小原理(Minimum Principle)によれば，前節の問題に対する最道 な制御入力 $\boldsymbol{u}$ は，ハミルトニアン(Hamiltonian)と 呼ばれるスカラ関数

$$
H=f(u)+\lambda^{T}(A x+B u)
$$

を各時刻において最小にする ${ }^{5)}$. 具体的な最適制御 u の形は, 後で問題ごとに与える.ここで，

$$
\lambda=\left[\lambda_{1}, \lambda_{2}, \lambda_{3}, \lambda_{1}\right]^{T}
$$

は運動方程式(状態方程式)に対する乗数べクトルで, 随伴変数などと呼ばれる. 評価関数 $(9)$ 式が最小とな るとき，随伴変数 $\lambda$ は次の微分方程式

$$
\frac{d \lambda}{d t}=-\left(\frac{\partial H}{\partial x}\right)^{T}=-A^{T} \lambda
$$

に従って変化する．ただし，状態変数の初期値・終端 值が全て指定されているため, 随伴変数の初期値・終 端值は，あらかじめ知ることはできない。

最適な制御 $\boldsymbol{u}$ および最適な軌道 $\boldsymbol{x}$ を求めるために は，境界条件(10)式を满足するように，状態変数の微 分方程式 (7) 式と随伴変数の微分方程式 (14) 式を連立 して解かなければならない。これは一般に非線形微分 方程式の二点境界值問題となるため, 解析的に最適解 を得ることは困難てある. 求解には繰り返し計算を含 んだ数值解法によらなければならない．

以下では，評価関数 $(9)$ 式の $f(\boldsymbol{u})$ に対して具体的 な形を与え，各場合についての最適な制御を示す。

(i ) $f=(1 / 2)|u|^{2}$ のとき(ただし，終端時刻 $t$ は 指定する)：この評価関数を最小にする制御入力は最 小エネルギー制御と呼ばれる。その最適な制御は次の ように表される。

$$
\boldsymbol{u}=\left\{\begin{array}{cl}
-\boldsymbol{p}, & |\boldsymbol{p}| \leq u_{\max } \text { のとき } \\
-\frac{\boldsymbol{p}}{|\boldsymbol{p}|} u_{\max }, & |\boldsymbol{p}|>u_{\max } \text { のとき }
\end{array}\right.
$$
ただし，

$$
\boldsymbol{p}=\boldsymbol{B}^{\boldsymbol{T}} \lambda=\left[\lambda_{s}, \lambda_{\mathrm{l}}\right]^{T}
$$


である.

（ii） $f=|u|$ のとき(ただし，終端時刻 $t_{f}$ は指定す る):この評価関数を最小にする制御入力は最小燃料 制御と呼ばれる．その最適な制御は次のような不連続 な関数となる。

$$
\boldsymbol{u}=\left\{\begin{array}{cc}
0, & |\boldsymbol{p}|<1 \text { のとき } \\
-\frac{\boldsymbol{p}}{|\boldsymbol{p}|} u_{\max }, & |\boldsymbol{p}|>1 \text { のとき }
\end{array}\right.
$$

随伴変数は連続であるから $|\boldsymbol{p}|$ もまた連続な関数であ る.したがって、最適な制御は推力を切ったコーステ イングと最大推力による加速の絽り返しになることが わかる.

(iii) $f=1$ のとき $\left(t_{f}\right.$ は不定とする):このとき評 価関数は $J=t_{f}$ となる.この評価関数を最小にする制 御入力は最短時間制御と呼ばれる。 その最適な制御は 次のように表される。

$$
u=-\frac{p}{|p|} u_{\max }
$$

すなわち，随伴変数べクトルの方向に最大推力を加え るのが最適な制御である。この問題では終端時間が不 定でハミルトニアン $H$ に時間 $t$ が陽に含まれないた め、最適な軌道では全制御区間にわたって

$$
H=0
$$

が成り立つ。

\section{5. 数值解法による最適解}

前節までに定義された最適制御問題の数値解法によ
る解を示す 用いた数值解法は，一般的な付帯条件つ き変分問題の解を求めることができる SGRA(the sequential gradient-restoration algorithm $)^{\theta)}$ と呼ば れるものである. 最適制御問題を変分問題として数值 的に解くと制御入力が本来不連続になるべき問題で も，制御入力が連続な関数として近似される．そのた めいわゆる1次(1st order)の計算法である SGRA て は精度の高い解を得ることができない ここではその 難点を克服するために入力が不連続になると予想され る問題に対しては時間軸折り返し法》と呼ばれる手法 を用いた。これは制御区間を制御入力が連続になる複 数の部分区間に分割し，全ての区間に対して同時に最 適化計算を行なう方法である。

以下に数值計算における仮定を述べる．ランデプの 目標は, 高度 $460 \mathrm{~km}$ 円軌道を周回しているものとす る.このときの周回角速度は $\omega_{0}=1.117 \times 10^{-3} \mathrm{rad} / \mathrm{s}$ となる. 宇宙機は初期時刻に目標の後方 $1000 \mathrm{~m}$ に停 止していて，飛行を行なった後に終端時刻に目標上に 停止するものとする，無次元化を行なうための長さに $1000 \mathrm{~m}$ という值を採用すれば，無次元の状態量に関 する境界条件は以下のようになる。

$$
x(0)=[-1,0,0,0]^{T} \quad x\left(t_{s}\right)=[0,0,0,0]^{T}(20)
$$

終端時刻を指定する問題では，終端時刻に目標の軌道 周期 $2 \pi / \omega_{0}$ の 0.5 倍を与えた．このとき無次元化され た終端時刻 $t_{f}$ は，

$$
t_{s}=\pi
$$

となる. 推力による加速度の制限值は $10^{-4} \mathrm{~g} \mathrm{~m} / \mathrm{s}^{2}$ と
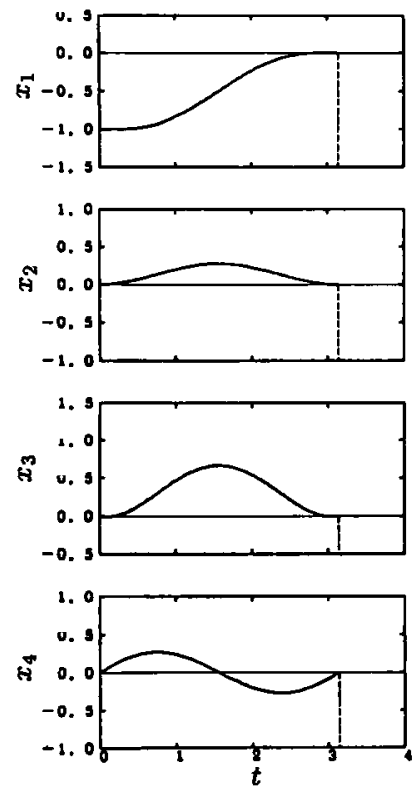

第 2 図
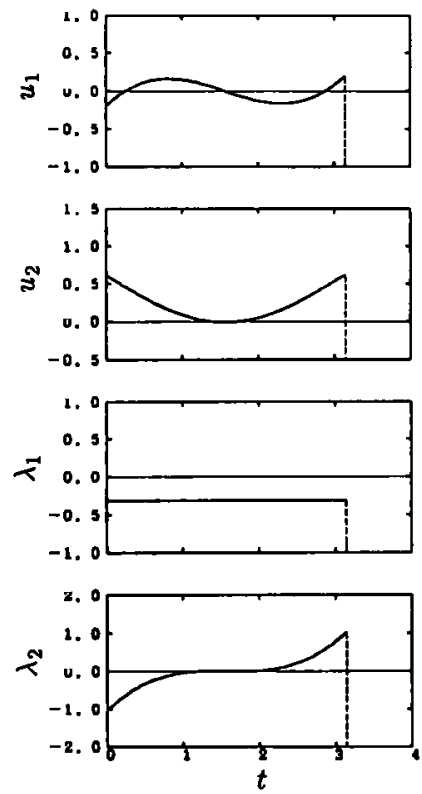
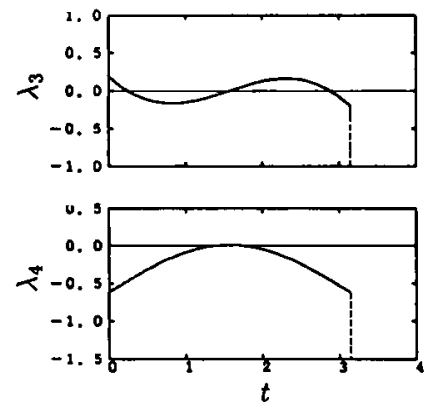


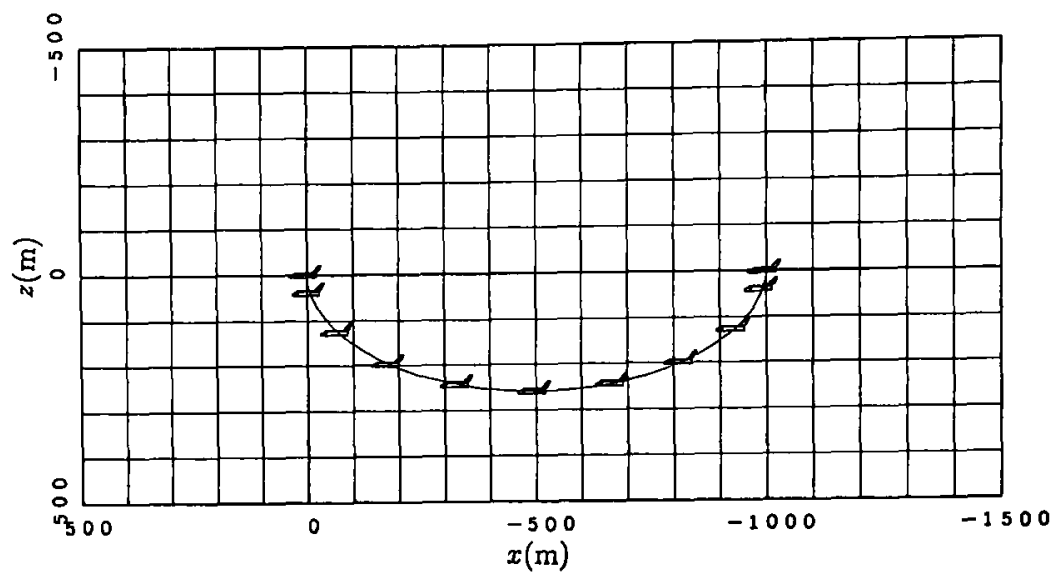

第3図 最小エネルギー制御問題の最適轨道
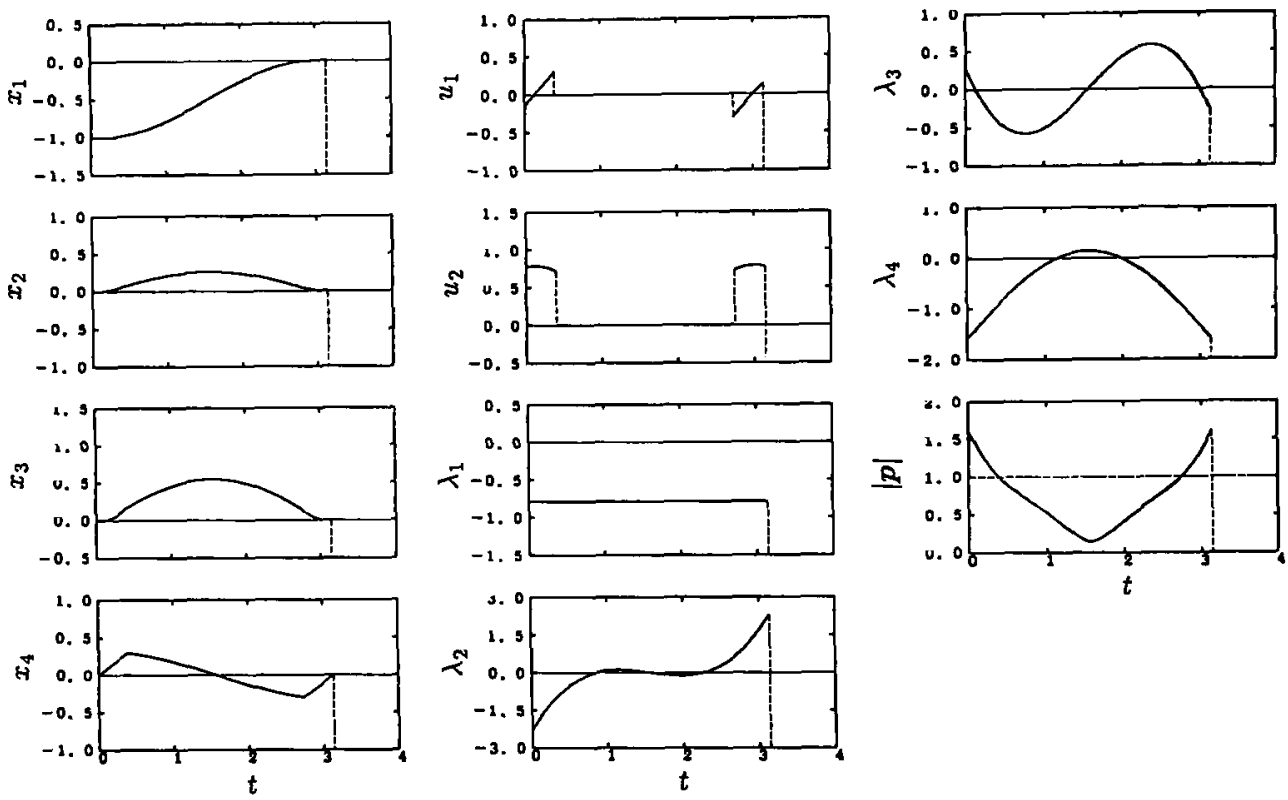

第 4 図

最小燃料制御問題の最適解

する，このとき，(11)式は，

$$
|u| \leq 0.786
$$

となる. 重力加速度 $g$ としては地球表面上の值 9.807 $\mathrm{m} / \mathrm{s}^{2}$ という值を用いた。

まず，最小エネルギー制御問題すなわち $f=$ $(1 / 2)|\boldsymbol{u}|^{2}$ の場合の最適解を第 2 図に示す。この計算例 では、制御入力は(22)式の制限にかからず，制御入力 $u_{1}, u_{2}$ は随伴変数 $\lambda_{s}, \lambda_{4}$ の符号を逆にしたものとな っている．第3図はこのときの最適軌道を示したもの である.この図における宇宙機は, 目標宇宙機の軌道
周期の 0.05 倍の時間ごとに描かれている.最適な軌 道は，宇宙機の進行方向に対して右向きに働くコリオ

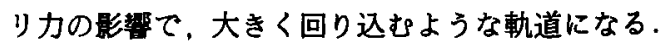

次に，最小燃料制御問題すなわち $f=|\boldsymbol{u}|$ の場合の 最適解を第 4 図に示す. 最適な制御は、出発した直後 と目的地点に到着する直前に最大推力を用い，その間 では推力を切るという形になる。この解法時間軸折り 返し法を用いて解いたものてある，第 5 図に、この場 合の最適軌道を示す。宇宙機に描かれている間隔は第 3 図と同じである，軌道制御の方法は最小エネルギー 


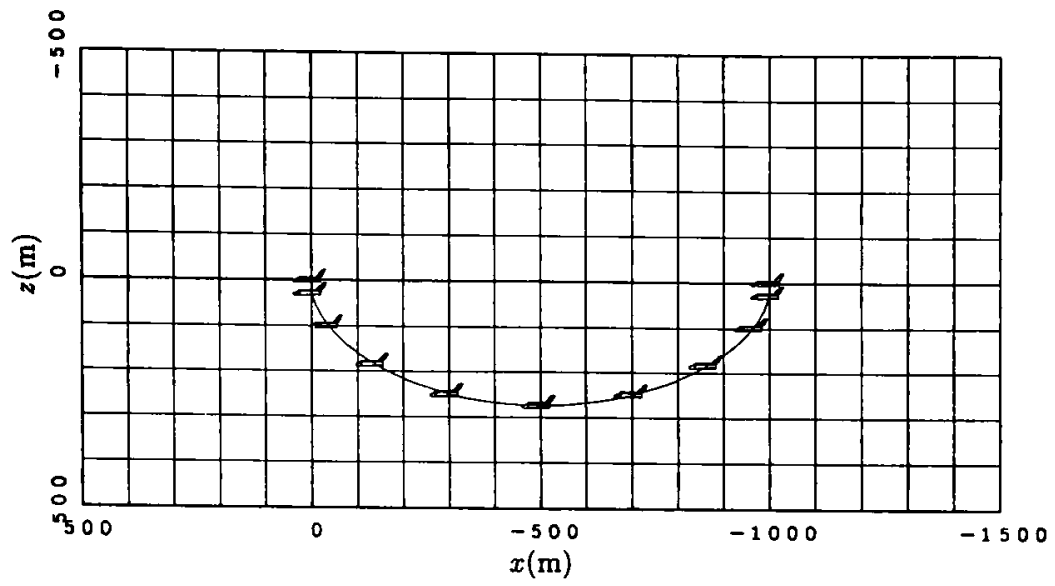

第 5 図 最小燃料制御問題の最总軌道
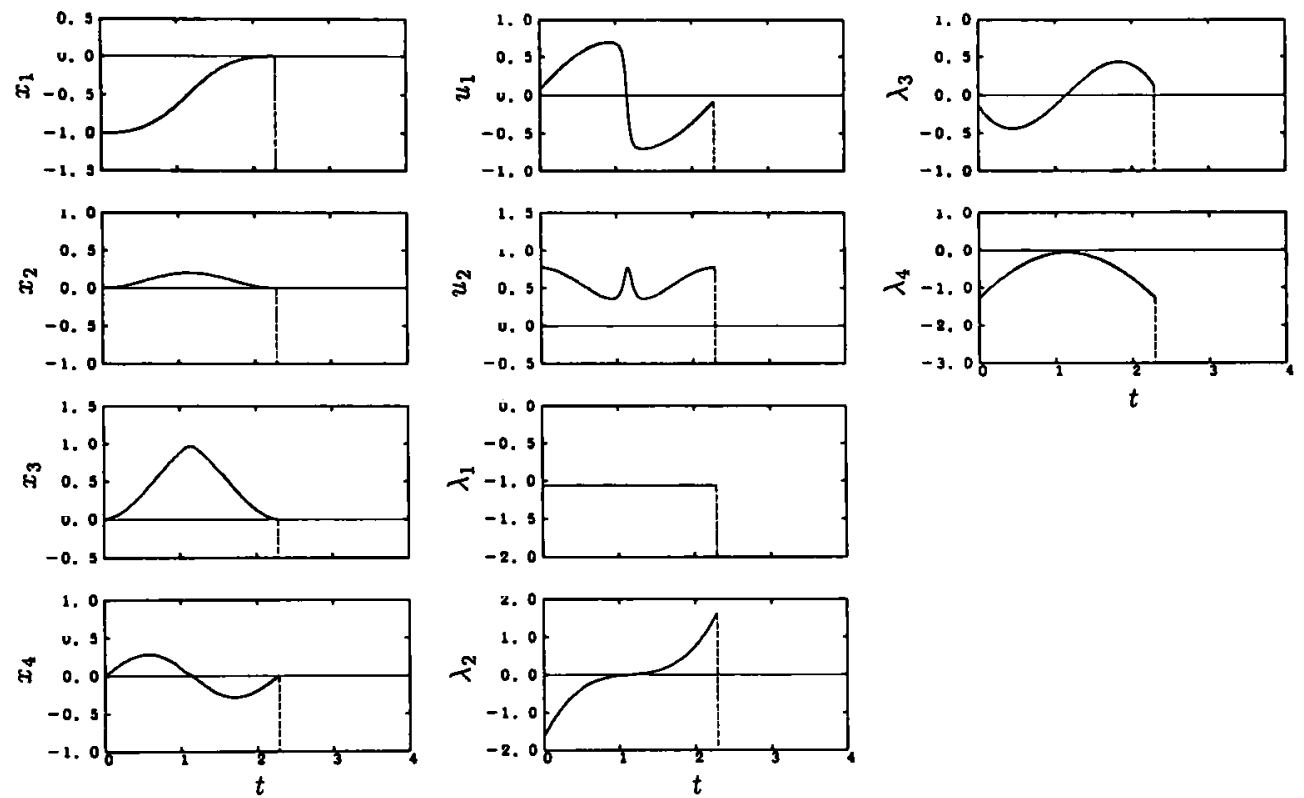

第 6 図 最短時間制御問題の最適解

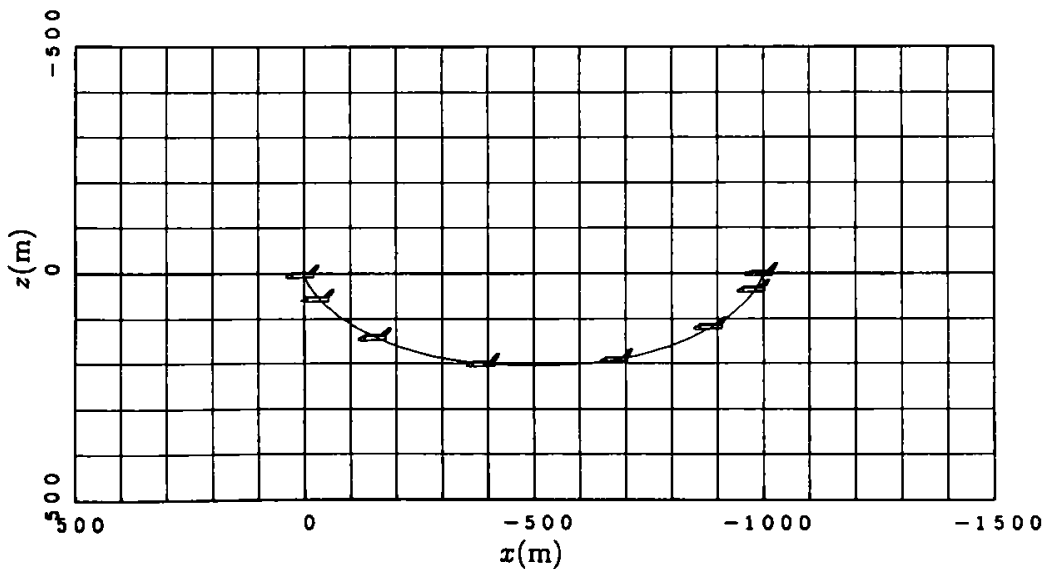

第 7 図 最短時間制御問題の最適軌道 
制御とは大きく異なるが、その最適軌道は，ほとんど 同じ形となる，楕円軌道をこのような座標系から見る とサイクロイド状の軌道になることが知られている が，推力を切っている部分はそのような棈円軌道の一 部になっていると考えられる。

最後に，最短時間制御問題すなわち $f=1$ の場合の 最適解を第 6 図に示す．前節で述べたように，最適な 制御はつねに最大推力を用いながら推力の方向を変化 させていくという形になる。数值計算の結果, 最適な 終端時刻は $t_{f}=2.289$ となった．実時間では，これは 軌道周期の 0.3643 倍に相当する. 第 7 図はこのとき の最適軌道を示したものである. 飛行時間を短くする ために，前の二つの場合に比べて軌道の回り込みが小 さくなってはいるが. 本質的には類似の軌道といえ る.

\section{6.おわりに}

本稿では，円軌道上の目標にランデブを行なう宇宙 機の軌道制御に最適制御理論を適用し，移動に必要な エネルギー，然料，時間という三種類の典型的な評価 関数を最小にする最適な制御を求めた.それぞれの問
題に対する最適な制御は，制御目的を反映して大きく 異なったものになることが解析と数值解によって示さ れた。

\section{参考文献}

1) Eggleston, J. M. : A Study of the Optimum Velocity Change to Intercept and Rendezvous, NASA TN D-1029 (1962).

2) Jezewski, D. J. and Donaldson, J. D. : An Analytic Approach to Optimal Rendezvous Using Clohessy. Wiltshire Equations, J. Astronaut. Sci., 27 (1979), pp. 293-310.

3) Redding, D. C., Adams, N. J. and Kubiak, E. T. : LinearQuadratic Stationkeeping for the STS Orbiter, J. of Guidance, Control and Dynamics, 12 (1989), pp. 248-255.

4) Clohessy, W. H. and Wiltshire, R. S.: Terminal Guidance System for Satellite Rendezvous, J. Aerospace Sci., 27 (1960), pp. 653-658 and 674.

5) Bryson, A. E. and Ho, Y. .C. : Applied Optimal Control, John Wiley \& Sons, 1975.

6) Gonzalez, S. and Miele, A.: Sequential GradientRestoration Algorithm for Optimal Control Problems with General Boundary Conditions, J. of Optimization Theory and Applications, 26 (1978), pp. 395-425.

7) 加藤寛一郎：工学的最適制御, 東京大学出版会, 1988. 